\title{
Nonlinear Summation of M- and L-Cone Inputs to Phasic Retinal Ganglion Cells of the Macaque
}

\author{
Barry B. Lee, ${ }^{1}$ Paul R. Martin, ${ }^{1}$ and Arne Valberg ${ }^{2}$ \\ 'Department of Neurobiology, Max Planck Institute for Biophysical Chemistry, D-3400 Göttingen, Federal Republic \\ of Germany, and ${ }^{2}$ Section of Biophysics, Department of Physics, University of Oslo, Oslo, Norway
}

\begin{abstract}
We have studied the responses of ganglion cells in the macaque retina to stimuli that alternate in color. With most color combinations, the phasic retinal ganglion cells, which sum input from $M$ - and L-cones in both center and surround, showed a response with twice the alternation frequency at equal luminance. This frequency doubling was directly related to the degree to which the $\mathrm{M}$ - and $\mathrm{L}$-cones were stimulated out-of-phase with one another, and thus varied with the wavelength combinations used. It was absent with wavelength combinations that lay along tritanopic confusion lines, when at equal luminance the $M$ - and $L$-cones are not modulated. Such a frequency-doubled response is evidence for a nonlinearity at or before $M$ - and L-cone summation. The effect became much smaller or was abolished when the receptive field center alone was stimulated, indicating that its mechanism lies in the surround or in a center-surround interaction. Also, it was much more marked at high luminance levels, being almost absent at retinal illuminances below 100 td. Its origin is not clear, but it seems to derive more from the L- than the M-cone. The results imply that phasic cells, through this nonlinearity, could respond to the red-green equal luminance borders used in some psychophysical experiments.
\end{abstract}

In the macaque retina there are 3 cone types, the L-, M-, and $\mathrm{S}$-cones. Later in the visual pathway, there exist 2 main cell systems. Phasic, nonopponent retinal ganglion cells project to the magnocellular layers of the lateral geniculate nucleus. Tonic, color-opponent ganglion cells project to the parvocellular layers of the nucleus (Wiesel and Hubel, 1966; de Monasterio and Gouras, 1975; Dreher et al., 1976; de Monasterio, 1978; Creutzfeldt et al., 1979; Perry et al., 1984). It is by virtue of antagonistic input from the different cone mechanisms that tonic cells display spectral opponency. The responses of tonic cells in the parvocellular layers of the lateral geniculate nucleus can be well described by assuming linear combination of the opponent cone inputs feeding center and surround (Lee et al., 1983, 1987b; Derrington et al., 1984; Valberg et al., 1987), although for more intense stimuli it is necessary to allow for the nonlinear rela-

Received June 8, 1988; revised Aug. 26, 1988; accepted Aug. 29, 1988

P.R.M. was supported by the Alexander von Humboldt Foundation. A.V. was supported by the Norwegian Research Council for Science and the Humanities. We thank Barbara Röser for technical assistance.

Correspondence should be addressed to Dr. B. B. Lee, Max Planck Institute for Biophysical Chemistry, D-3400 Göttingen, Federal Republic of Germany.

Copyright @ 1989 Society for Neuroscience $0270-6474 / 89 / 041433-10 \$ 02.00 / 0$ tionship between the intensity of incident light and çone excitation (Naka and Rushton, 1966; Boynton and Whitten, 1970).

Unlike tonic cells, phasic cells receive summed input from M- and L-cones to both center and surround (de Monasterio, 1978). When wavelengths that differentially activate these cones are alternated, it is possible to stimulate the $\mathrm{M}$ - and L-cones half-a-cycle out-of-phase with one another. This permits testing for linearity of $\mathrm{M}$ - and $\mathrm{L}$-cone summation. If cone inputs were summed linearly by phasic cells, it should be possible to abolish a cell's response completely by adjusting the relative intensities of the 2 wavelengths. In the course of experiments with this type of stimulus, termed heterochromatic flicker, with certain wavelength combinations we found it impossible to completely abolish phasic cells' responses, a residual response being present at twice the flicker frequency. This phenomenon was first noted, under different stimulus conditions, by Schiller and Colby (1983).

Such evidence of nonlinear summation is of interest because models of receptive field structure in which input elements summate in a linear manner have been applied to cells of the visual system for many years (e.g., Rodieck, 1965). In particular, linearity of spatial summation has become established as an important criterion for cell classification. The presence of nonlinear summation is, for example, the defining feature of Y-cells of the cat retina (Enroth-Cugell and Robson, 1966). However, tests for linearity of spatial summation do not reliably distinguish between the phasic and tonic cell systems of the monkey. Some degree of nonlinearity of spatial summation is present only in a minority of phasic, magnocellular cells (Kaplan and Shapley, 1982; Blakemore and Vital-Durand, 1986).

In this paper, we provide evidence for a nonlinearity in Mand L-cone summation in phasic ganglion cells; the effect was present in all cells tested. We attempt to delimit the mechanisms that may be involved and discuss implications for psychophysics.

\section{Materials and Methods}

The activity of ganglion cells was recorded from the retinas of juvenile macaques ( $M$. fascicularis). Animals were anesthetized initially with an intramuscular injection of ketamine and thereafter with halothane in a $70 \% / 30 \% \mathrm{~N}_{2} \mathrm{O} / \mathrm{O}_{2}$ mixture (1-2\% during surgery, followed by $0.2-1 \%$ during recording). Local anesthetic was applied to points of surgical intervention, especially around the eye. EEG and the electrocardiogram were monitored continuously as a control for anesthetic depth. Muscular relaxation was attained by intravenous infusion of gallamine triethiodide $(5 \mathrm{mg} / \mathrm{kg} / \mathrm{hr}$ ) together with ca. $3 \mathrm{ml} / \mathrm{hr}$ of dextrose Ringer's. Endtidal $\mathrm{pCO}_{2}$ was kept near $4 \%$ by adjusting the rate and depth of ventilation, and body temperature was maintained near $37.5^{\circ} \mathrm{C}$. To record from retinal ganglion cells, a cuff of conjuctiva was first sewn to a metal ring. Following removal of a section of bony orbit, a cannula was inserted 
through the sclera, and an electrode lowered onto the retina. The eyes were focused onto a screen $57 \mathrm{~cm}$ lrom the animal with appropriate contact lenses. A 6 mm artificial pupil was usually used. Clarity of the optic media was checked frequently, and when the smaller retinal vessels could no longer be recognized, recording from that eye was terminated, and the second eye prepared. On completion of recording the animals were killed with an overdose of barbiturate.

Ganglion cells were classified as phasic or tonic using spots of various colors. We drew on extensive experience with cells in the lateral genic-

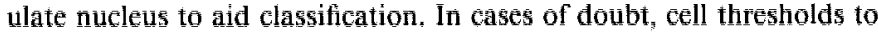
achromatic contrast were estimated; this is a reliable means of distinguishing phasic from tonic cells in the different layers of the lateral geticulate nuclẹs (Kaplan and Shapley, 1982; Hicks et al, 1983), In addition, responses to a series of equiluminant chromatic stimuli were usually stored as a record of a cell's spectral responsiveness and the time course of its responses.

Visual stimuli were generated with a 3-chañnel optical stimulator, each having as a light source a tungsten filament lamp (Prado Universal, Leitz), providing white light with chromaticity coordinates $(x, y)=$ $(0.404,0.410)$. Crossed Polaroid filters were placcd before 2 of the projectors. The beams were combined and passed through a rotating Polaroid disc, which enabled us to alternate different spectral mixtures sinusoidally. One channel provided a background if necessary. The stimulus beam was combined with the background and back-projected upon a tangent screen. We routinely used a $4^{\circ}$ stimulus field but frequently recorded responses with a $0.5^{\circ}$ field for purposes of comparison. Stops for producing different stimulus sizes were placed after the Polaroid filters.

We were concerned that spectral or spatial nonuniformity in the optical system could have caused artifactual frequency-doubled responses. Several tests were carried out to rule out this possibility. First, luminance over the receptive field was monitored using a Photo Research SpectraSpotmeter. The output of the photometer closely approximated a sinusoid and at equal luminance it was unmodulated and artifact-free. Second, as described below, alternation of white with white or of tritanopic pairs of stimuli did not produce a frequency-doubled response. Third, with small spots or at low luminance levels, no frequency-doubled response was present. None of these manipulations should affect a spectral artifact. Last, we tested 3 cells with a diffuser placed in front of the stimulus. This produced an amorphous flickering patch without distinct boundaries. Strong frequency-doubled responses were observed. A spatial artifact can thus also be excluded. We thus conclude that imperfections in the stimulus conditions did nol generale spurious frequency-doubled responses.

Spectral composition of stimuli was adjusted with interference filters (Schott, NAL, half-bandwidth at half-maximum, $25 \mathrm{~nm}$ ) and intensities could be adjusted with neutral density filters. Filter wheels with 10 slots allowed a sequence of stimuli to be preselected. These wheels were inserted into the stimulus beams and controlled by a computer system that also averaged and stored unit responses. An analog output from the spot photometer was also stored to give us a record of the luminance over a cell's receptive field.

A Photo Research 702A/703A Scanning Spectrophotometer was used to measure the luminance $\left(2^{\circ}\right)$ and chromaticity coordinates of the stimuli. The luminance levels measured with it were within $10 \%$ of those of the spot photometer. Since cell receptive fields were parafoveal, we used photometric values based on the $10^{\circ} V_{\lambda}$ curve. To calculate these values, we integrated the product of the spectral power distribution, $P(\lambda)$, of the light with the transmission of the interference filters, $\tau_{c}(\lambda)$, the transmission of the Polaroids, $\tau_{\mathrm{p}}(\lambda)$, and the $10^{\circ} V_{\lambda}$ function,

$$
L=\int_{380}^{760} P(\lambda) \tau_{\mathrm{c}}(\lambda) \tau_{\mathrm{p}}(\lambda) V_{10(\lambda)} d \lambda
$$

as described in Valberg et al. (1987). These calculated values corresponded well with the $2^{\circ}$ measured values for wavelengths above 500 $\mathrm{nm}$, as to be expected. Precise comparison of $V_{\lambda}$ of man and monkey has not been carried out, but the available measurements (DeValois et al., 1974) suggest they are similar. We have used the human $V_{\mathrm{x}}$ function on the assumption that it is very close to that of the monkey.

The amount of cone excitation, $S$, produced by a given color was calculated by integrating the product of the spectral power distribution, $P(\lambda)$, of the light with the spectral sensitivity of the cone fundamentals, $s(\lambda)$, and the total transmission of the filters, $\tau(\lambda), S=\int_{380}^{760} s(\lambda) P(\lambda) \tau(\lambda)$ $d \lambda$, as dercribed in Valberg et al. (1987). For the different filters, these values were normalized to the cone excitation produced by our white light of the same luminance, to give values $R$ and $G$ for the $L$ - and $M=$ cones. We could then calculate the relative amplitudes of each cone's modulation for different filter and luminance conditions. When 2 lights,

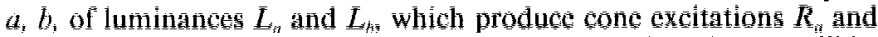
$R_{h}$ in $\mathrm{L}$-cones and $G_{x}$ and $G_{b} \mathrm{M}$-concos are oxchanged, each coné will be

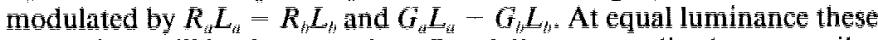
expressions will be the same since $R$ and $G$ are nomalized to an equilu= minant white light. The Michelson contrast generated in each cone is

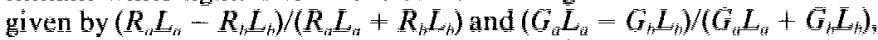
and all contrastis given here are derived in this way.

Flicker was usually carried out around a mean luminance of $50 \mathrm{~cd} /$ $\mathrm{m}^{2}$ giving a retinal illumination of 1400 td. Cells had receptive fields $3^{5}-15^{s}$ from the fovea. We recorded responses of about 160 ganglion cells to heterochromatic and luminance flicker. The results reported here were obtained from 57 phasic cells subjected to heterochromatic Hicker. A more extensive description of cell responses to the different kinds of flicker employed is to be reported elsewhere (Lee et al., 1988 , $1989 \mathrm{a}, \mathrm{b})$.

Halothane retards dark adaptation following a blcach (van Norren and Padmos, 1974). Since mean adaptation level stayed relatively constant in these experiments, and the halothane concentration was relatively low, it is unlikely that it could have influenced the responses recorded.

\section{Results}

When 2 spectral mixtures are sinusoidally alternated, at say 10 $\mathrm{Hz}$, the resulting stimulus paradigm is one of heterochromatic flicker. Human subjects, by altering the relative intensities of the flickering lights, are able to minimize or abolish the sensation of flicker, and the 2 lights are then defined as of equal luminance. The human photopic luminosity, or $V_{\lambda}$, function was defined in this way. It is generally assumed that the $V_{\lambda}$ function is a sum of M- and L-cone excitations (see Boynton, 1979).

When different wavelengths were alternated with a standard white stimulus, the amplitude of a phasic ganglion cell's responses went through a minimum at relative intensities that corresponded very closely to the $V_{\lambda}$ function (Lee et al., 1987a, 1988). However, for certain wavelength combinations there often remained a clear response in phasic cells at twice the flicker frequency.

Figure $1 A$ illustrates this phenomenon. The averaged responses of a phasic on-center cell to 2 cycles of heterochromatic flicker between $622 \mathrm{~nm}$ and white light are shown. We increased the luminance ratio $\left(L_{\lambda}: L_{w}, 622 \mathrm{~nm}\right.$ : white) in steps, as indicated by the numbers with each histogram; a schematic representation of the stimulus is shown on the left. At low luminance ratios, the response at the fundamental frequency is dominant. When stimuli were approximately of equal luminance, the cell responds at twice the frequency of flicker. When a substantial luminance imbalance is reintroduced, the frequency-doubled component disappears. As a control, we also show in Figure $1 \mathrm{~A}$ a set of histograms generated when white was alternated with white, other conditions being identical. The cell's response is completely abolished under this condition at equal luminance.

Figure $1 B$ demonstrates a further example from another phasic cell, in this case when $440 \mathrm{~nm}$ was alternated with white. At equal luminance, a clear frequency-doubled response is present, though inspection of the histograms reveals differences in detail compared with the example in Figure $1 A$.

Not all wavelength combinations generated a frequency-doubled response. For example, in Figure $1 C$ are shown the responses of the same cell as in Figure $1 B$ when a light of $570 \mathrm{~nm}$ was flickered against white. No frequency-doubled response ap- 

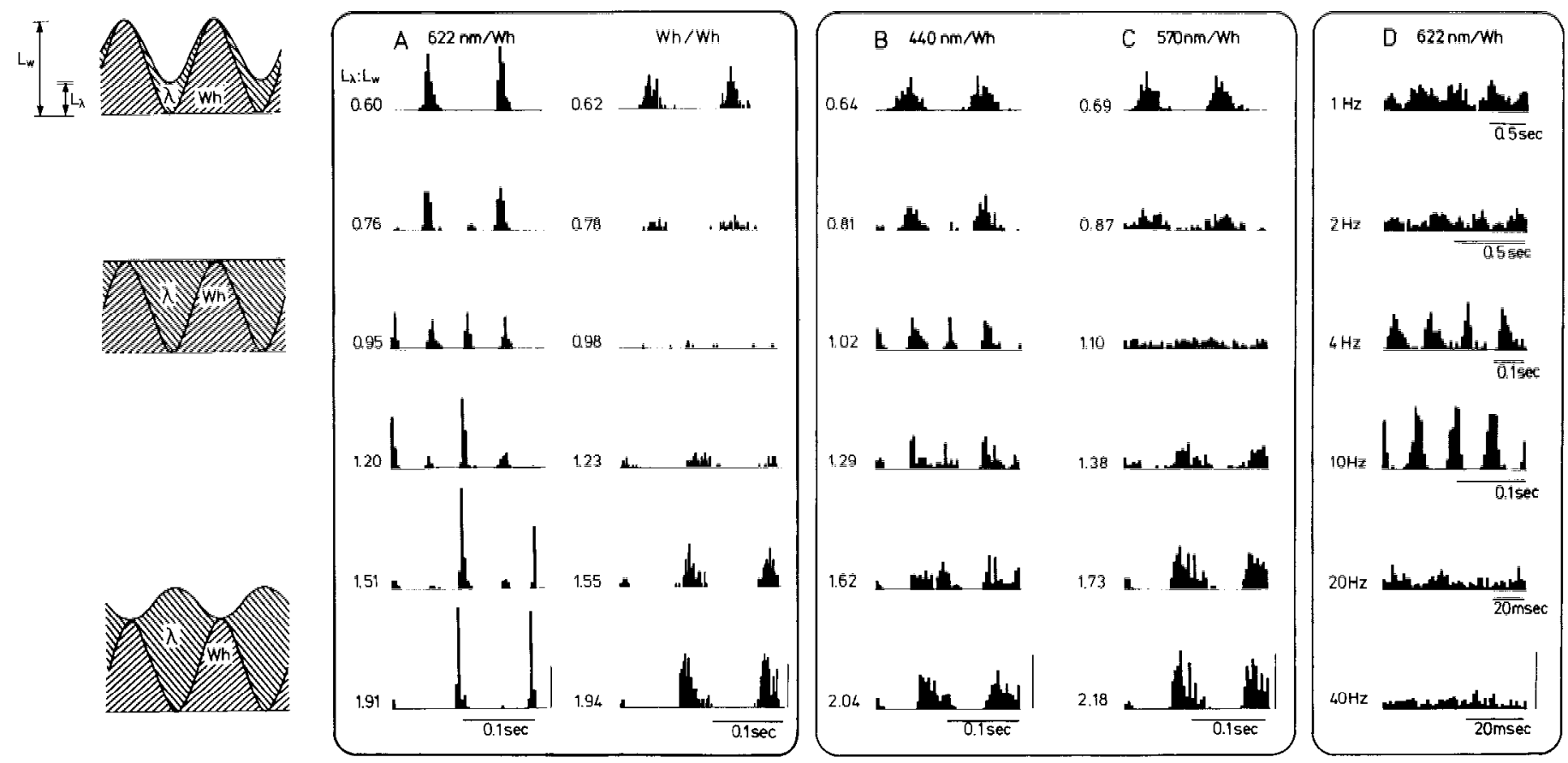

Figure 1. A, Responses of an off-center phasic cell to heterochromatic flicker at $10 \mathrm{~Hz}$ at different luminance ratios of $622 \mathrm{~nm}$ to white light, as indicated by values with each histogram. A sketch of the flicker composition is on the left-hand side. Two cycles of flicker are represented in each histogram. Close to equal luminance, a frequency-doubled response appears. With white/white flicker under identical conditions it is absent. $B$ and $C$, Responses of a phasic off-center cell to $440 \mathrm{~nm}$ :white and $570 \mathrm{~nm}$ :white $10 \mathrm{~Hz}$ flicker. No frequency-doubled response occurs in the latter instance, when L- and M-cones are unmodulated. $D$, Responses of a phasic on-center cell to $622 \mathrm{~nm}$ :white flicker at different stimulus frequencies at equal luminance; a response at twice the stimulus frequency occurs in all histograms except at $40 \mathrm{~Hz}$. Calibration bars, 100 impulses/sec. Generally, 4-6 sec of activity were averaged for each histogram, and 50 bins were allocated to each cycle.

pears, the cell's activity not being modulated close to equal luminance.

To analyze quantitatively response histograms such as those in Figure 1, we calculated the amplitudes of the first and higher harmonics in the response by Fourier analysis. In Figure 2, $A-$ $C$ are plotted the first- and second-harmonic components of the responses of the cells shown in Figure 1, $A-C$. On the abscissa we have used the luminance ratio between the flicker components, so that a ratio of one indicates equal luminance.

In all 3 graphs, the amplitude of the first harmonic (open circles) goes through a minimum close to equal luminance. When the first-harmonic component is large, a second-harmonic component (filled circles) is also present, for the response waveform is not sinusoidal, containing significant higher-harmonic components. The presence of a second-harmonic component when the first harmonic is large is trivial, but it can be seen in Figure $2, A, B$ that close to equal luminance the second-harmonic component becomes much larger than the first harmonic. In Figure $2 C$, with the stimuli situated on a tritanopic confusion line, both first- and second-harmonic components disappear at equal luminance.

Frequency-doubled responses were seen in all 57 phasic cells studied, and the curves of Figure 2, $A-C$ were typical for all cells recorded, although the magnitude of the second harmonic was dependent on the wavelengths in the flicker and varied from cell to cell, as will be documented in Figures 3 and 4. No difference was found between on- and off-center cells.

If present at only one temporal frequency, it could be argued that this effect is due to some peculiarity in the temporal pattern of response. If this were so, a frequency-doubled effect should be dependent on temporal frequency. Accordingly, we tested 10 cells at a number of different frequencies between 1 and $40 \mathrm{~Hz}$. In all cases the frequency-doubled response was present over this range, except at $40 \mathrm{~Hz}$. For example, in Figure $1 D$ are shown histograms ( 2 cycles in each case) obtained from a phasic cell when $622 \mathrm{~nm}$ was alternated with white at different temporal frequencies at equal luminance. At all frequencies except $40 \mathrm{~Hz}$ a second-harmonic component was present, though it is less apparent at the lower temporal frequencies.

Phasic cells respond poorly to luminance flicker at low temporal frequencies anyway (Hicks et al., 1983; Derrington et al., 1984), so the temporal frequency dependence of the frequencydoubled response could be due to the temporal characteristics of the cell's response per se. We therefore compared the amplitudes of the second-harmonic components from Figure $1 D$ with the temporal frequency tuning of the cell estimated from responses to achromatic flicker (Fig. 2D). For the latter, we plotted the amplitude of the first harmonic for a modulation depth producing about the same cone contrast as the $622 \mathrm{~nm}-$ white flicker. The shapes of the response curves do not differ markedly, except at $40 \mathrm{~Hz}$. This also held for other neurons tested. Thus, the frequency-doubled response was present over a wide range of temporal frequencies, and its frequency tuning appeared similar to that of the first harmonic. An origin of the effect as a simple latency phenomenon can thus be ruled out.

\section{Dependence on wavelength of flicker components}

The amplitude of the residual second-harmonic component varied according to the spectral mixtures in the flicker. It was very pronounced for long wavelengths (e.g., $684 \mathrm{~nm}$, Fig. 5) but was always absent for flicker along tritanopic confusion lines. Along such a line in a cone excitation space, at equal luminance, both 
Figure 2. $A-C$, The amplitudes of the first- and second-harmonic compo= nents obtained by Fourier analysis of the responses of the cells in Figure $1 A-$ $C$ plotted against the luminance ratio of the components in the heterochromatic flicker. In $A(622 \mathrm{~nm}$ :white) and $B$ (440 nm:white), close to equal luminance the second-harmonic components becomes dominant. For flicker along a tritanopic confusion line $(C, 570$ $\mathrm{nm}$ :white), the second-harmonic component is absent. The arrows indicate the luminance ratios at which silent substitution occurred. The left arrow in $A$ marks M-cone flicker (silent L-cone) and the right arrow L-cone flicker (silent M-cone). In $B$, the opposite holds true. $D$ presents a comparison of the amplitudes of the frequency-doubled component for the cell of Figure $1 D$ with the amplitude of the fundamental component of a response to white flicker of approximately the same cone contrast (ca. $25 \%$ ). The amplitudes have been plotted relative to flicker frequency. No great difference in tuning is apparent.
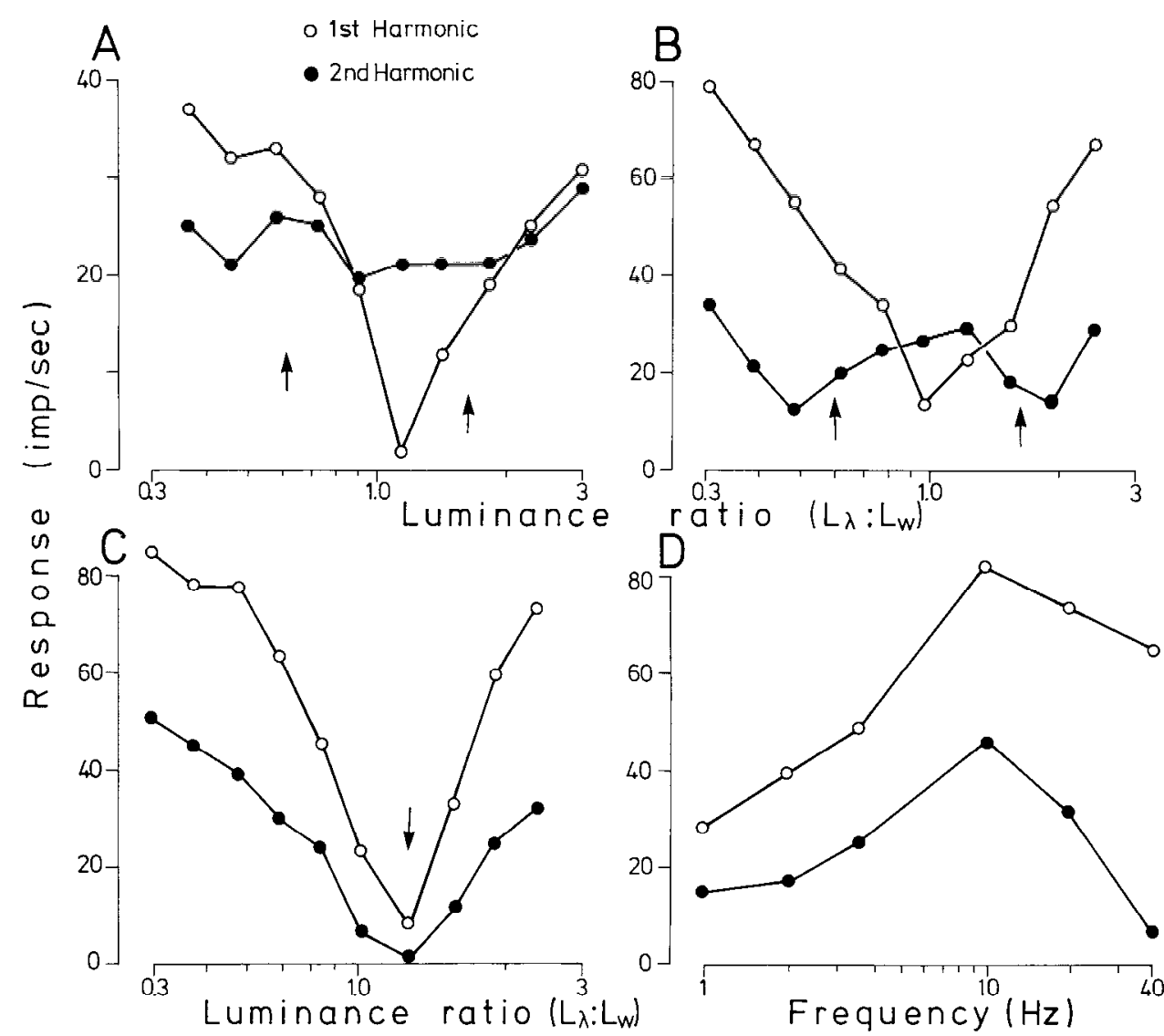

M- and L-cones are unmodulated and only S-cones give a modulated signal. Tritanopic observers are unable to distinguish such stimuli. White alternated with $570 \mathrm{~nm}$ at equal luminance is such a stimulus combination, as illustrated in Figures $1 C$ and $2 C$. We also tested on 4 cells $412 \mathrm{~nm}$ alternated with $528 \mathrm{~nm}$, another pair of tritanopic stimuli. No frequency-doubled response was present.

These results strongly suggest that a nonlinearity on summation of the $\mathrm{M}$ - and L-cone mechanisms is occurring and that this is responsible for the response at twice the fundamental frequency. We interpret the phenomenon as follows.

When a large luminance difference between 2 alternating lights is present, both cones are stimulated in phase, and the fundamental dominates the response. However, with, for example, red-green flicker with the components close to equal luminance, the M- and L-cones are stimulated $180^{\circ}$ out of phase. During the half-cycle when the proportion of red light is increasing in the mixture, excitation increases for the L-cone and decreases for the M-cone, while in the other half of the cycle the opposite occurs. This is a necessary consequence of the $V_{\lambda}$ function being made up of a sum of $\mathrm{M}$ - and L-cones.

If summation were linear, $\mathrm{M}$ - and L-cone signals would cancel. A nonlinearity might well result in the frequency-doubled responses seen. If stimuli lie along tritanopic confusion lines, neither cone will be modulated at equal luminance. With such flicker, activity of phasic cells was not modulated at equal luminance.

If the above interpretation were correct, then the amplitude of the frequency-doubled response at equal luminance should be related to the degree to which the cones are activated in antiphase. The further away 2 wavelengths lie from a tritanopic confusion line, the greater will be the M- and L-cone modulation and the larger should be the frequency-doubled response. To test this, we derived a measure of the out-of-phase cone signal at equal luminance for different pairs of alternating colors. We used this measure, which is proportional to the $|R-G|$ cone signal, because Michelson contrast differs between the cones under these conditions. An identical measure was used by Valberg and Tansley (1977).

For 26 phasic cells, we tested a variety of spectral combinations with the heterochromatic flicker paradigm. Figure 3 (open circles) shows the second-harmonic amplitude obtained from a Fourier analysis of cell responses plotted as a function of $\mid R-$ $G \mid$ cone modulation at equal luminance for 4 typical cells. The different points mostly represent flicker with white alternated with a particular wavelength, but red-green flicker was also used.

For all cells, there was a clear relationship between the amplitude of the frequency-doubled response at equal luminance and $|R-G|$ cone modulation, as exemplified in the cells of Figure 3. The extent to which second-harmonic components were apparent varied from cell to cell, as may be seen from the variation in slopes of the relationships for the cells in Figure 3.

The points in Figure 3 seem to fall close to straight lines, and we have therefore drawn least-squares regression lines through them, with correlation coefficients as indicated. For the 26 cells, the correlation coefficient, $r$, varied between 0.72 and 0.97 , with a mean of 0.90 . The mean slopes of the regression lines was 33.4 impulses per unit of cone excitation $(n=26, \sigma=11.7)$. Values for the cells in Figure 3 are given in the legend. It is noteworthy that the regression lines passed close to the origin. 


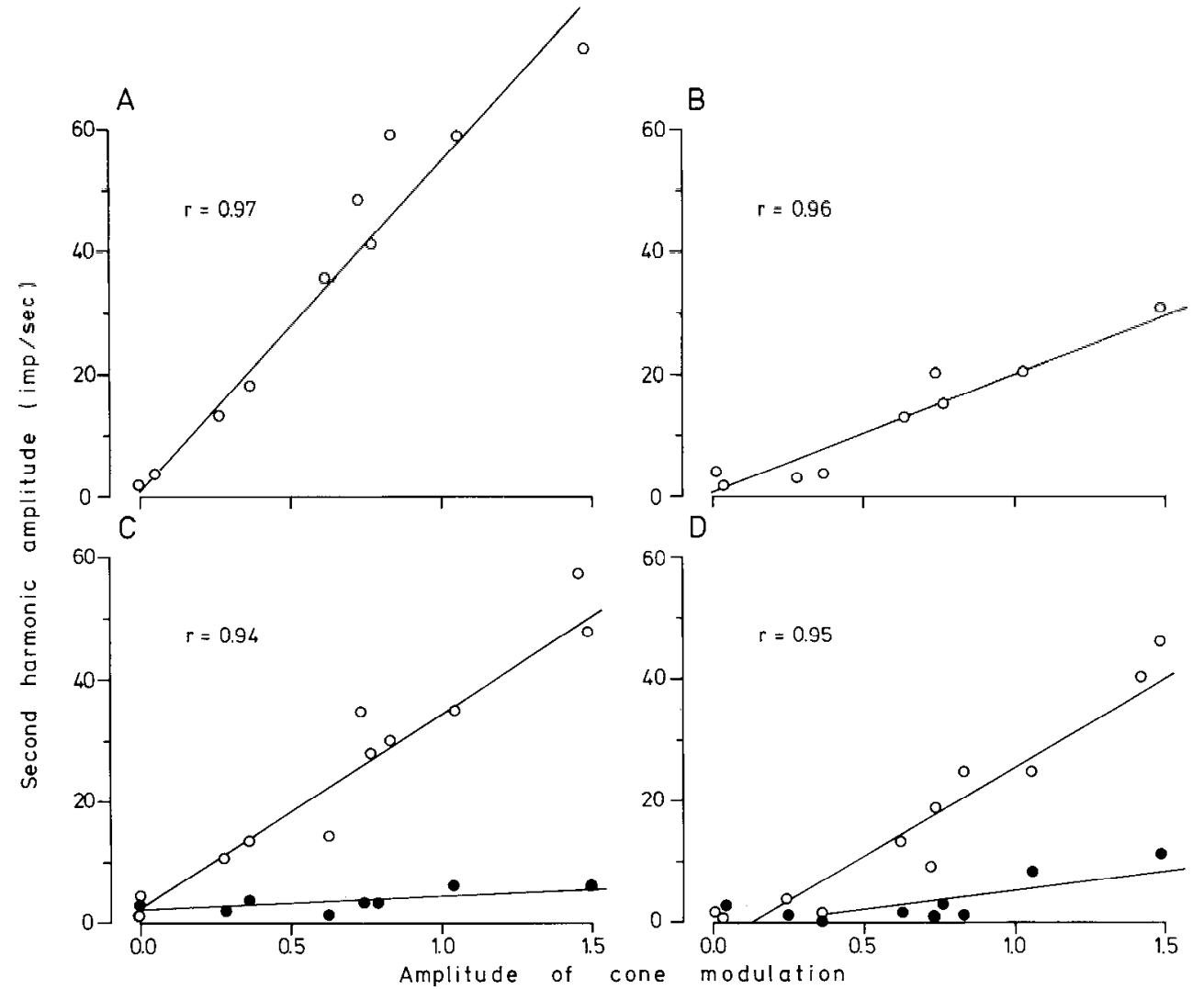

Figure 3. $A-D$, Plots showing depen= dence of the amplitude of the secondharmonic component at equal luminance $\left(50 \mathrm{~cd} / \mathrm{m}^{2}\right)$ on the modulation amplitude of the cones derived as described in the text, modulation of $\mathrm{M}$ and L-cones being the same. Four different cells are shown. The units of cone modulation have been normalized relative to modulation for an achromatic stimulus; $100 \%$ modulation of a white stimulus of $25 \mathrm{~cd} / \mathrm{m}^{2}$ mean luminance would produce one unit of modulation. Regression lines have been drawn for each cell, correlation coefficients being as indicated. Slopes are as follows: $A$ $53 ; B, 19 ; C, 47$; and $D, 30$ impulses per unit of conc cxcitation. The sccond harmonic is large with stimulation of a $4^{\circ}$ field (open circles). With a $0.5^{\circ}$ field (filled circles), the second-harmonic component is largely absent, slopes being as follows: $C, 5$, and $D, 8$ impulses per unit of cone excitation.
The mean $y$-axis intercept was $3.1(n=26, \sigma=4.0)$, which was similar to the value obtained from a Fourier analysis of maintained activity. Thus, a differential modulation of the $\mathrm{M}$ - and L-cones at equal luminance does not have to exceed a threshold before a frequency-doubled response becomes apparent.

As the ratio of intensities of 2 flickering lights are altered so that the axis of flicker tilts out of the equal luminance plane of a cone excitation space, there will be ratios at which either the $\mathrm{M}$ - or L-cone is unmodulated, this paradigm being termed silent substitution for the M- or L-cone. The way these ratios can be calculated is described under Materials and Methods. For clarity, we will here refer to the modulated cone mechanism, M-cone flicker for silent L-cone substitution and L-conc flicker for silent $\mathrm{M}$-cone substitution. The ratios at which $\mathrm{M}$ - and L-cone flicker occur are illustrated by arrows in Figure 2 . Between the arrows, the $\mathrm{M}$ - and L-cones are modulated in antiphase by the heterochromatic flicker. For $570 \mathrm{~nm}$ : white flicker, the 2 lights are so close to a tritanopic confusion line that at equal luminance the $\mathrm{M}$ - and L-cones are unmodulated and there is only one arrow. For the examples in Figure 2, it is between the arrows that the second-harmonic component becomes equal to or larger than the first harmonic. This qualitative observation supports the suggestion that out-of-phase modulation of the Mand L-cones is necessary for a frequency-doubled response to occur.

We conclude that for a frequency-doubled response to be present, the $\mathrm{M}$ - and L-cones must be modulated in antiphase and that the size of the response is linearly related to the degree of counterphase cone modulation. This is in accord with the notion that the some kinds of nonlinearity at the point of $\mathrm{M}$ and L-cone summation is occurring.

\section{Localization of second-harmonic component}

To determine if the mechanism that might be responsible for this effect was present in both center and surround, we tested if a frequency-doubled response was present if the flickering stimulus was restricted to the receptive field center. Instead of a $4^{\circ}$ field, a $0.5^{\circ}$ flickering spot was used. This should easily be large enough to completely fill the center of parafoveal phasic cells, as their expected center size is $0.12^{\circ}-0.4^{\circ}$ (de Monasterio and Gouras, 1975; Crook et al., 1988).

Figure 4 shows results from such an experiment. For heterochromatic flicker between white and $440 \mathrm{~nm}$, with a $4^{\circ}$ stimulus a marked frequency-doubled response was present (Fig. $4 A$ ). When a flickering spot of $0.5^{\circ}$ was used, the second-harmonic component was absent at equal luminance (Fig. $4 B$ ). In Figure $4, C, D$ cell responses have been quantified in the same way as in Figure 2. With the $4^{\circ}$ stimulus, a large second-harmonic component is clearly present at equal luminance, but it is absent with the smaller stimulus (Fig. $4 D$ ). For small and large fields the fundamental response component was equally vigorous when a luminance imbalance was present.

A substantial reduction or elimination of second-harmonic components occurred with all 10 cells tested with small stimuli. For 8 cells, we tested a range of wavelengths with small spots. Two of the cells in Figure $3, C, D$ were tested with small spots and amplitudes of the second-harmonic components at equal luminance for the different cone modulations plotted (filled symbols). These points and regression lines lie much below those for $4^{\circ}$ stimuli. Averaged over 8 cells, this reduction in slope of the regression line was from 36.9 to 11.0 impulses per unit of cone excitation with the smaller spot size $(\sigma=10.8$ and 8.1, 
Figure 4. Responses of phasic on-center cell to $440 \mathrm{~nm}$ :white flicker with a $4^{\circ}(A)$ and a $0.5^{\circ}(B)$ stimulus. Luminance ratios are indicated. At equal luminance the larger stimulus evokes a frequency-doubled response, which disappears when a small stimulus is used. A quantitative analysis is shown in $C$ and $D$, where the amplitudes of the first and second harmonics are plotted against luminance ratio. Calibration bar in $A$ and $B, 100$ impulses $/ \mathrm{sec}$, $10 \mathrm{~Hz}$ flicker.
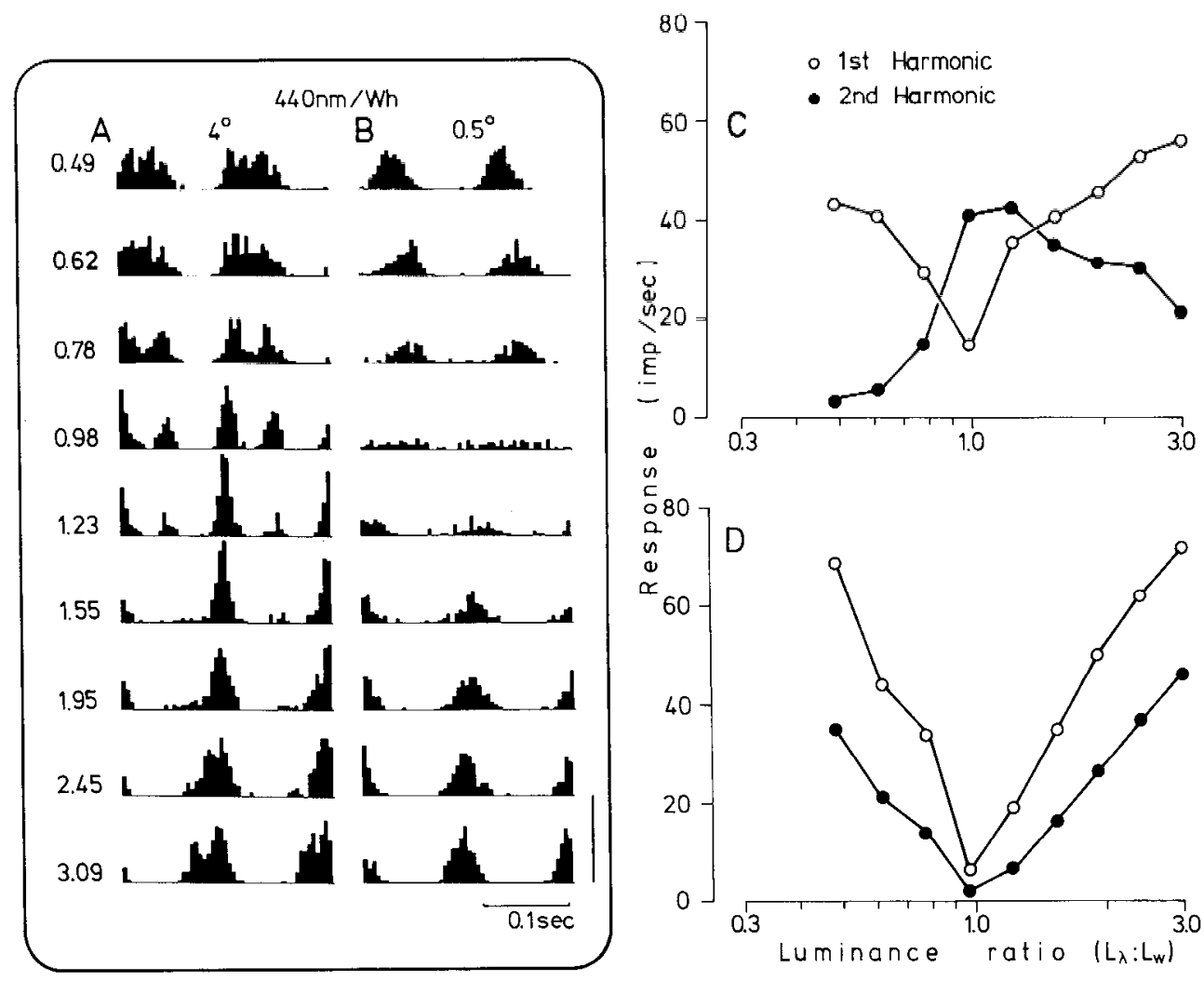

respectively, $n=8)$. It is possible that any residual, frequencydoubled component may be because the spot size used $\left(0.5^{\circ}\right)$ was large enough to significantly activate the surround mechanism.

We conclude that the frequency-doubled effect observed requires stimulation of the receptive field surround. In an attempt to isolate the surround response, we used flickering annuli, but they evoked poor responses.

\section{Effect of adaptation level}

In heterochromatic flicker photometry, similar psychophysical results are obtained at different adaptation levels, except that at high retinal illuminances subjects report difficulties due to residual flicker. We tested 7 phasic cells at different adaptation levels, ranging from the usual retinal illuminance of $1400 \mathrm{td}$ down to $44 \mathrm{td}$. The amplitude of the first-harmonic components went through a minimum at luminance ratius cluse to one independent of retinal illuminance. At 44 td, the spectral sensitivity of phasic cells still clearly matched the photopic rather than the scotopic luminosity function and was thus determined by the cones.

However, for all cells, the amplitude of second-harmonic components at equal luminance decreased markedly with decreasing mean retinal illuminance, until at an illuminance of 44 td little second-harmonic component was present. This is illustrated in Figure 5. The histograms show the response of a phasic cell to heterochromatic flicker between $684 \mathrm{~nm}$ and white at equal luminance. With this wavelength, the second-harmonic component was very marked at 1400 td but decreased at lower illuminances until at 44 td no second-harmonic component was present. The amplitudes of the first- and second-harmonic components at 44 and 1400 td are plotted in Figure 5, B, C. At the lower luminance level, both first- and second-harmonic components of the cell's response are almost abolished near a luminance ratio of one, but at the higher level the second-harmonic component is very marked. The amplitudes of first-harmonic components are comparable in Figure $5, B, C$.

It would thus appear that the nonlinearity responsible for the frequency-doubled response only becomes apparent as retinal illuminance is increased above the mesopic into the photopic range. The results of Figure 5 are of interest in view of some psychophysical results discussed below.

\section{Origin of frequency-doubled component}

The occurrence of a response at twice the stimulation frequency is evidence of some kind of nonlinearity. Since with center stimulation alone, no frequency-doubled response was present, the center appears to be able to sum M- and L-cone signals linearly. The mechanism of this nonlinearity of the surround is not readily obvious, and 2 factors make its investigation difficult. First, as the effect requires activation of the surround, any model must be couched in terms of surround modification of the center signal. The fact that poor responses were obtained with flickering annuli would imply the surround is to some extent "silent," and this is in itself an indication of nonlinearity. Second, the characteristics of the signals from $\mathrm{M}$ - and L-cones reaching the surround may be different. Since no frequency-doubled response was present when just the center was stimulated, any such difference presumably does not originate in the cones themselves but somewhere between the cones and the point of summation in the surround mechanism.

Inspection of histograms with heterochromatic flicker suggested that a difference between $\mathrm{M}$ - and L-cone cone mechanisms might be present, as judged from the shape of response 


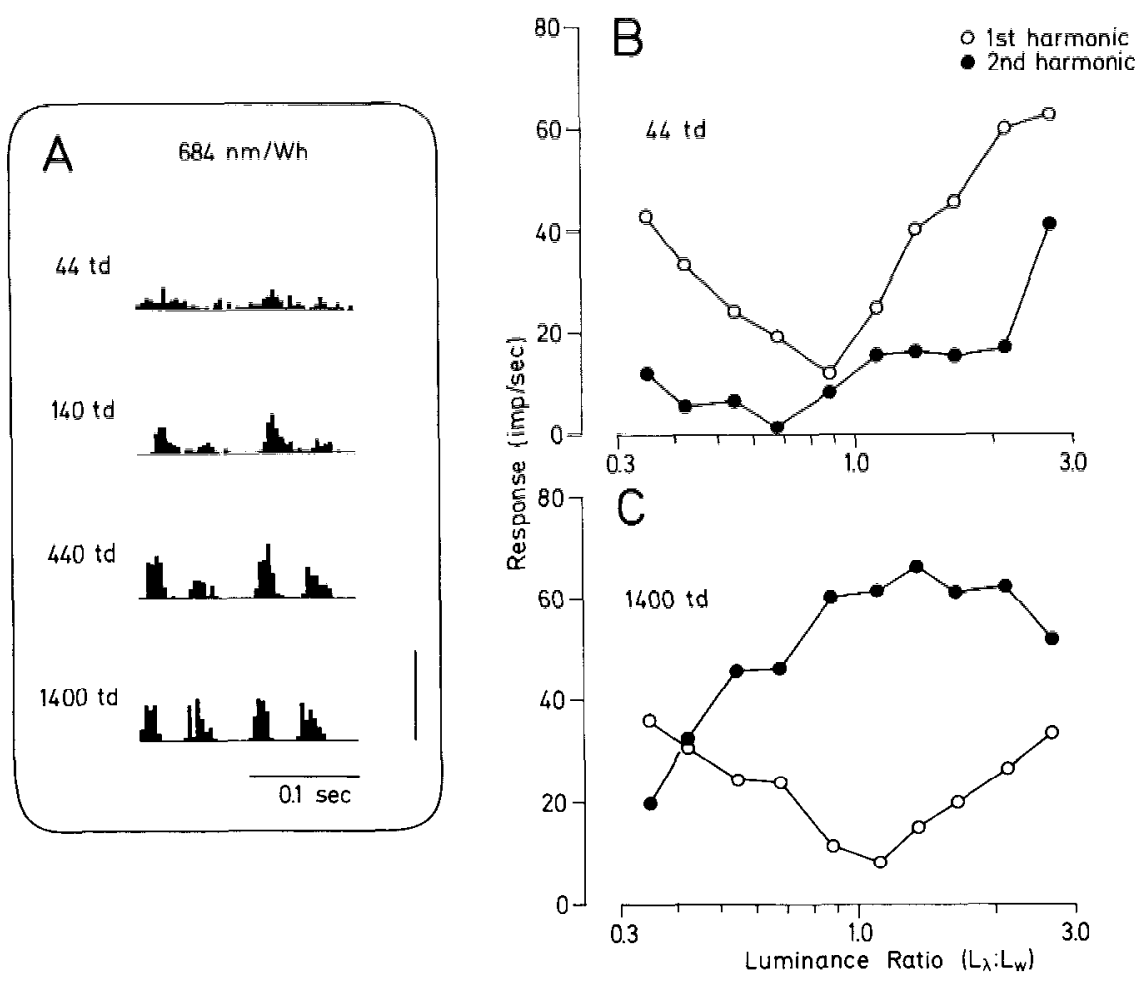

Figure 5. A, Responses of a phasic oncenter cell to $684 \mathrm{~nm} /$ white flicker (10 $\mathrm{Hz}$ ) at equal luminance at 4 different levels of retinal illuminance. The frequency-doubled response disappears at low retinal illumination. Calibration bar, $100 \mathrm{impulses} / \mathrm{sec} . B$ and $C$ show a quantitative analysis of the first- and second-harmonic components at the highest and lowest illumination levels. histograms at luminance ratios at which $\mathrm{M}$ - or L-cone flicker occurred. To test this possibility, we studied 10 phasic cells with $622 / 528 \mathrm{~nm}$ flicker, the relative luminances of the components being adjusted so as to generate $\mathrm{M}$ - or L-cone flicker. The stimulus was projected upon a $570 \mathrm{~nm}$ background (total mean illuminance, $1400 \mathrm{td}$ ), and various contrasts for each cone mechanism could be provided.

Figure $6 A$ shows the responses of a phasic on-center cell to $\mathrm{M}$ - and L-cone flicker for $4^{\circ}$ and $0.5^{\circ}$ stimuli. Responses to equal luminance flicker are also shown. Contrast for the modulated cone mechanism was about $15 \%$ in each case and was about $15 \%$ for both cones in the equal luminance condition.

For the $4^{\circ}$ stimulus, the sinusoidal stimulus waveform is distorted in the response of the cell for both M- and L-cone flicker conditions. Insofar as this distortion arises prior to the point of summation, adding such waveforms would be likely to leave a residual response, and the histogram recorded with equal luminance flicker (with equivalent cone contrasts) shows a substantial frequency-doubled component.

It is possible that some distortion of cone inputs might follow summation, but this would be expected to influence signals from both cones equally. For the $4^{\circ}$ field, it can be seen that the response histograms for $\mathrm{L}$-cone flicker show more distortion than for M-cone flicker. As a measure of distortion, we took the ratio of the sum of harmonics 2-6 to the fundamental, and then compared these ratios for $\mathrm{M}$ - and L-cone flicker over the 11 cells tested. The same cone contrasts $(15 \%)$ at the same mean luminance level were used for the comparison. Values obtained ranged from 0.80 to 2.53 for M-cone flicker, and 1.66 to 3.39 for L-cone flicker. On average, harmonic distortion for L-cone flicker was 1.61 times greater than for M-cone flicker ( $\sigma=0.56$, $n=11$ ), this difference being significant at the $1 \%$ level. This suggests that prior to cone summation in the surround the L-cone signal undergoes more distortion than the M-cone signal.

Inspection of response histograms also revealed that with small spots or at low luminance levels responses become more sinusoidal in waveform, less harmonic distortion being present. Figure 6 also shows response histograms with a $0.5^{\circ}$ spot, under the same stimulus conditions as with the $4^{\circ}$ field. The response looks more sinusoidal in shape with the smaller stimulus, especially for L-cone flicker.

To quantify this difference, we calculated estimates of distortion as described above for the 8 cells tested with small and large stimulus fields. For $642 \mathrm{~nm} /$ white flicker, the mean distortion ratio was reduced from $2.22(\sigma=0.92)$ to $1.18(\sigma=0.24)$ for M-cone flicker on reducing stimulus size, and from 8.08 ( $\sigma$ $=4.79)$ to $1.53(\sigma=0.65)$ for L-cone flicker, both these changes being significant at the $1 \%$ level.

These results again suggest more distortion in L- than in $\mathrm{M}$-cones occurs prior to summation. The mechanism of this distortion, be it a rectifying nonlinearity as in Y-cells of the cat retina (Hochstein and Shapley, 1976) or some other mechanism requires further study. However, the phase of frequency-doubled responses at equal luminance was variable among cells (Fig. 1), which suggests the mechanism may not be easy to define.

A further result obtained using $\mathrm{M}$ - and L-cone flicker is illustrated in Figure 6, $B, C$. The amplitudes of first- and secondharmonic components are plotted against increasing modulation depth for $\mathrm{M}$ - and L-cone flicker and for equal luminance flicker; in the latter case it is the contrast for the individual cones that has been used. With M- and L-cone flicker, increasing contrast results in a gradual increase of both first- and secondharmonic components, with the former being dominant. At equal luminance, the second-harmonic component is the dom- 
A

Figure $6 . \quad$ A, Responses of a phasic coll to $\mathbf{M}$-cone, $\mathbf{L}$-cone, and equal luminance flicker between 622 and $528 \mathrm{~nm}$. Individual cone contrast was about $15 \%$ in each case; $4^{\circ}$ and $0.5^{\circ}$ stimuli were used. With the larger stimulus, harmonic distortion of the responses to $\mathrm{M}$ and $\mathrm{L}$-cone flicker and a frequencydoubled response at equal luminance were much more apparent than with the smaller stimulus. Frequency, $10 \mathrm{~Hz}$; calibration bar, 100 impulses/sec, $B-D$, Quantitative analyses of responses of a phasic cell to increasing modulation depths for $622 \mathrm{~nm} / 528 \mathrm{~nm}$ flicker for $\mathrm{M}$ - and L-cone flicker and at cqual luminance. It is apparent that the threshold for generation of a frequency-doubled response is quite close to the thresholds of the individual cone mechanisms.

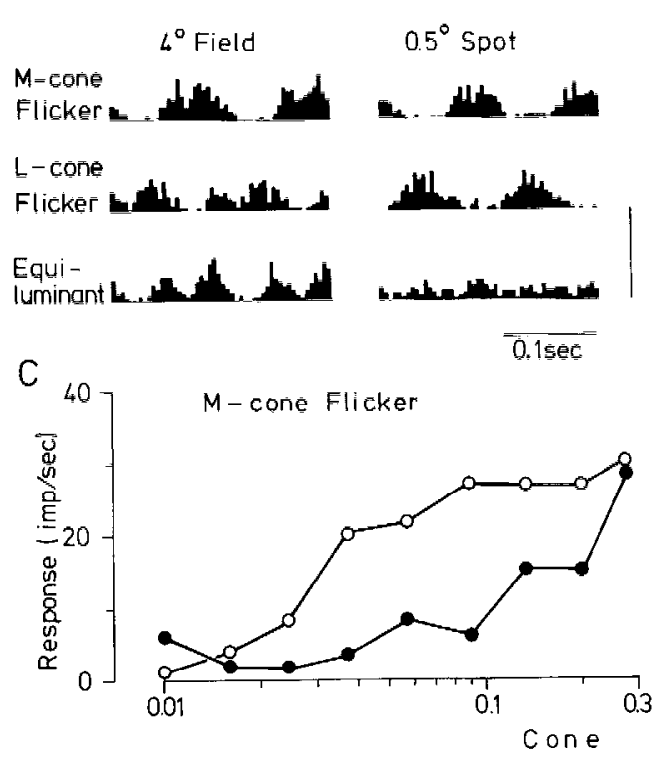

B
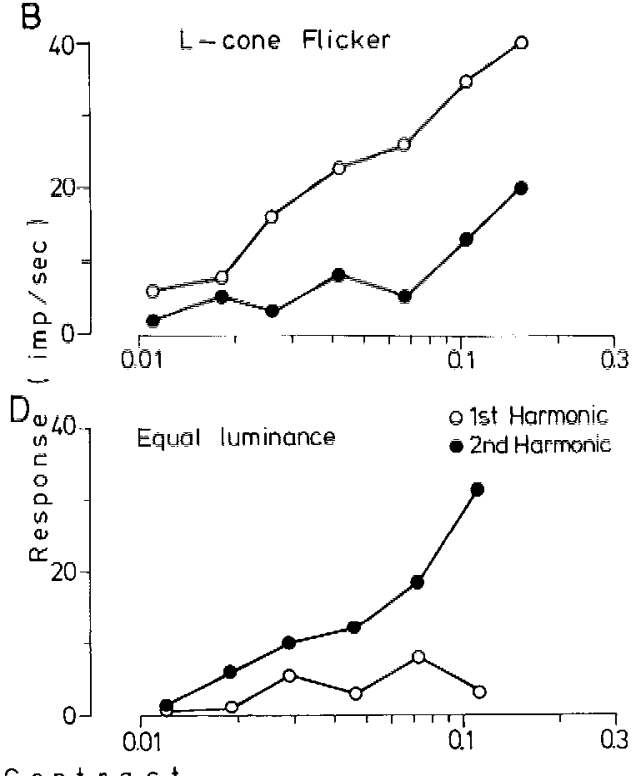

iunl luminance - 2nd Harmonic

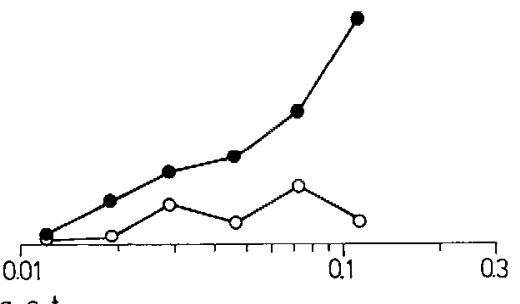

inant one. As might be predicted from Figure 3, a significant frequency-doubled response is present at cone contrasts not much above $\mathrm{M}$ - and L-cone flicker thresholds.

\section{Discussion}

The presence of a response at twice the stimulus frequency is a clear indication of nonlinearity. The frequency-doubled responses seen in Figure 1 are, in this respect, analogous to the frequency-doubled responses seen in Y-cells of the cat retina when testing for linearity of spatial summation by contrast reversal (Enroth-Cugell and Robson, 1966). When a sine-wave grating is appropriately situated over a Y-cell's receptive field, contrast reversal leads to a response at twice the reversal frequency. For $\mathrm{Y}$-cells in the cat this nonlinearity has been attributed to subunits in the receptive field (Hochstein and Shapley, 1976).

We have demonstrated here a nonlinearity revealed on summation of the M- and L-cone inputs to phasic ganglion cells of the macaque. Though most cells in the phasic, magnocellular layers of the lateral geniculate nucleus show linear spatial summation (Kaplan and Shapley, 1982; Blakemore and Vital-Durand, 1986), their and our findings are not incompatible. First, achromatic contrast reversal stimulates both cones in phase, and so a nonlinearity in cone summation may not be so apparent. Second, the $4^{\circ}$ stimulus used here corresponds to a spatial frequency low (ca. 0.125 cycles $/ \mathrm{deg}$ ) compared with that usually employed in contrast reversal tests. We show in Figure 4 that with small spots (and thus at higher spatial frequencies) more linear behavior is to be observed.

We did not test for linearity of spatial summation in our experiments, but since every phasic cell recorded displayed a frequency-doubled response, it is likely that cells with linear spatial summation were represented in our sample. In all cells, mixed $\mathrm{M}$ - and L-cone inputs to the center mechanism could be demonstrated (Lee et al., 1988a), but we did not test if the effect was more marked in phasic cells with a red-sensitive surrounds, as is the case for the Type IV cells of Wiesel and Hubel (1966). It remains to be seen if phasic cells with nonlinear spatial summation may show nonlinearity of $\mathrm{M}$ - and L-cone summation to a more marked degree. It will be of interest if linearity of spatial summation in phasic ganglion cells should prove to be dependent on retinal illuminance, as we show here for linearity of $\mathrm{M}$ - and L-cone summation.

All tonic cells from the parvocellular layers of the lateral geniculate nucleus show linear spatial summation. For these wavelength-opponent cells, for achromatic flicker the cone mechanisms will act antagonistically. We tested over 100 tonic ganglion cells with achromatic flicker, but in no cell with only $\mathrm{M}$ - and L-cone input was any frequency-doubled response seen, and this is consistent with linear summation of cone signals. In some cells with S-cone input, higher-harmonic components were sometimes present in responses, but their origin is obscure.

A response at each phase of a red-green substitution at equal luminance was first noted by Schiller and Colby (1983) in cells of the magnocellular layers of the geniculate nucleus, but they were uncertain as to its origin. They used low temporal frequencies, and it is possible this might have accentuated the response due to differential adaptation of $\mathrm{M}$ - and $\mathrm{L}$-cones. We found the effect at all temporal frequencies below $40 \mathrm{~Hz}$. It is difficult to calculate cone contrast for their data. On the other hand, Derrington et al. (1984), measuring responses to flicker generated on a video display, seldom found frequency-doubled responses with heterochromatic flicker. However, the chromatic modulation used by them was probably too limited to evoke substantial frequency-doubled responses; we calculated we could provide an out-of-phase cone signal at least 6 times larger than they employed. Further, background responses to the $60 \mathrm{~Hz}$ frame rate they used could have led to second-harmonic components being less readily distinguishable.

Many possibilities exist as to the source of the nonlinearities observed. Obvious candidates are a rectifying nonlinearity, as in the spatial subunits in the receptive fields of $Y$-cells of the cat retina (Hochstein and Shapley, 1976), or a compressive or saturating nonlinearity (Boynton and Whitten, 1971), as seen in some of the late receptor potential recordings of Baron and Boynton (1975).

The L-cone signal reaching the surround seems to be more distorted than the M-cone signal. Since the center sums the cone 
signals linearly, this difference cannot be in the cones themselves but at some later stage. Whatever the mechanism responsible, it must be able to account for the results in Figure 3, in which we have shown a linear relationship between the second-harmonic amplitude at equal luminance and the out-of-phase cone signal. A saturating nonlinearity would not readily lead to such a result, but a rectifying nonlinearity might do so. Also, the harmonic composition at ratios around equal luminance should also be predicted by a valid model.

\section{Psychophysical considerations}

Heterochromatic flicker photometry was devised as a means of determining the spectral sensitivity of a human observer, and it was largely on the basis of data obtained by this method that the photopic luminosity function was defined by the CIE in 1924. As the relative intensity of 2 flickering lights is changed, the sensation of flicker can be minimized or abolished by a human subject, and the lights are then defined as of equal lu= minance.

We show elsewhere that minimization of phasic cell responses underlies this psychophysical task (Lee et al. 1987a, 1988). The mean spectral sensitivity of phasic cells, as judged from minima of the fundamental response component as shown in Figure 2, closely corresponds to that determined psychophysically, with a variability between cells of about $20 \%$. Such minima are independent of temporal frequency, and obey laws of linearity such as additivity and transitivity, which are important properties psychophysically. These results are described extensively elsewhere (Lee et al., 1988).

One requirement of the analysis presented here is that the $V_{\lambda}$ functions of man and macaque are similar. DeValois et al. (1974) found this to be the case, although there were some deviations at the spectral extremes in comparison with the $2^{\circ}$ curve. DeValois et al. (1974) themselves point out, howcver, that their simian subjects were able to use the peripheral retina. This and a field size of more than $4^{\circ}$ would lead to the reported deviations from the $2^{\circ}$ curve at the spectral extremes. It is also important to note that the cones of man and macaque are virtually identical in their spectral properties (Bowmaker and Dartnall, 1980; Bowmaker et al., 1980; Nunn et al., 1984; Baylor et al., 1987), so that the $V_{\lambda}$ function, as a sum of M- and L-cones, would be expected to be rather similar in the 2 species.

The presence of frequency-doubled responses might be expected to interfere with flicker photometry and contribute to variability. Psychophysically, it is seldom possible to eliminate residual flicker completely. It is feasible that this residual flicker partly derives from the frequency-doubled responses of phasic cell responses at equal luminance, although variation in the $M / L$ cone balance among individual phasic cells or a contribution from tonic cells could also be responsible. With long wavelengths (e.g., 682 or $642 \mathrm{~nm}$ ), residual flicker becomes so marked that heterochromatic flicker photometry becomes difficult at high retinal illuminances (J. Pokorny, personal communication). It is just under these conditions that the frequencydoubled responses of phasic cells become very vigorous (Fig. 5).

We argue elsewhere (Lee et al., 1989b) that high temporal frequency signals from tonic cells are not perceived as flicker. It is of interest that Swanson et al. (1987) suggested that a luminance mechanism contributes to detection of chromatic flicker at high temporal frequencies. This could have a phys- iological substrate in the frequency-doubled responses from phasic cells.

Our results are also relevant to data obtained using other psychophysical paradigms. For example, it is possible to generate the $V_{\lambda}$ function using the minimal distinct border technique (Boynton and Kaiser, 1968; Wagner and Boynton, 1972). This method involves the juxtaposition of 2 fields of different wave= lengths, the relative intensities of which are adjusted until the border is minimally distinct. The relative spectral sensitivity function so generated matches the $V_{\mathrm{\lambda}}$ function. If the nonlinearity described here is also present when a chromatic border is moved across the receptive field, phasic ganglion cells could provide a residual signal when no luminance difference is prescnt. Such a signal would contain only spatial and no chromatic information for the response would be independent of the direction of chromatic contrast.

Valberg and Tansley (1977) described a proportional relationship between the residual distinctness of a border at equal luminance and the $|R-G|$ cone difference signal. If the linear relationship shown in Figure 3 also holds for moving borders, the results in Figure 3 would thus closely resemble this relation between border distinctness and the $|R-G|$ difference signal (Valberg and Tansley, 1977; Fig. 7). Both the shape of the curves and their slopes are similar, although absolute sensitivity differs. The same relationship has been established for pattern-evoked cortical potentials with equal luminance patterns (Tansley et al., 1983), suggesting such potentials could partially derive from the phasic cell pathway.

More recently, Livingstone and Hubel (1987) have reviewed paradigms in which there is a degradation in perceptual performance with chromatic patterns having no luminance difference, at illuminance levels quite comparable to those at which we found frequency-doubled responses. It is generally assumed that with such patterns the "luminance channel" provides no signal at a chromatic border. If this channel has as a physiological substrate the phasic magnocellular system (Lee et al., 1988), then nonlincarity in $\mathbf{M}$ - and L-cone summation may provide such a signal from phasic cells. The assumption that a luminance channel does not provide a signal with such patterns may then have to be reexamined.

\section{References}

Baron, W. S., and R. M. Boynton (1975) Responses of primate cones to sinusoidally flickering homochromatic stimuli. J. Physiol. (Lond.) 246: 613-646.

Baylor, D. A., B. J. Nunn, and J. L. Schnapf (1987) Spectral sensitivity of cones of the monkey Macaca fascicularis. J. Physiol. (Lond.) 390: $145-160$.

Blakemore, C., and F. Vital-Durand (1986) Organization and postnatal development of the monkey's lateral geniculate nucleus. J. Physiol. (Lond.) 380: 453-491.

Bowmaker, J. K., and H. J. A. Dartnall (1980) Visual pigments of rods and cones in a human retina. J. Physiol. (Lond.) 298: 501-511.

Bowmaker, J. K., H. J. A. Dartnall, and J. D. Mollon (1980) Microspectrophotometric demonstration of four classes of photoreceptor in an old world primate (Macaca fascicularis). J. Physiol. (Lond.) 298: $131-144$

Boynton, R. M. (1979) Human Color Vision, Holt, Rinehart and Winston, New York.

Boynton, R. M., and P. K. Kaiser (1968) Vision; The additivity law made to work for heterochromatic photometry with bipartite fields. Science 161: 366-368.

Boynton, R. M., and D. N. Whitten (1970) Visual adaptation in monkey cones; recordings of late receptor potentials. Science 170: 14231426.

Creutzfeldt, O. D., B. B. Lee, and A. Elepfandt (1979) A quantitative 
study of chromatic organisalion and receptive fields of cells in the lateral geniculate body of the rhesus monkey. Exp. Brain Res. 35: $527-545$.

Crook, J. M., B. Lange-Malecki, B. B. Lee, and A. Valberg (1988) Visual resolution of macaque retinal ganglion cells. J. Physiol. (Lond.) 392: 193-211.

de Monasterio, F, M. (1978) Properties of concentrically organised X and $Y$ ganglion cells of macaque retina. J. Neurophysiol. 41: 1394 $141 \overline{7}$.

de Monasterio, F. M., and P. Goūras (1975) Functional properties of ganglion cells of the rhesus monkey retina. J. Physiol. (Lond.) $25 I$ : $167-195$.

Derrington, A. M., J. Krauskopf, and P. Lennie (1984) Chromatic mechanisms in lateral geniculate nucleus of macaque. J. Physiol. (Lond.) 357: 219-240.

DeValois, R. L., H. C. Morgan, M. C. Polson, W. R. Mead, and E. M. Hull (1974) Psychophysical studies of monkey vision. 1. Macaque luminosity and colour vision tests. Vision Res. 14:53-67.

Dreher, B., Y. Fukuda, and R. W. Rodieck (1976) Identification, classification and anatomical segregation of cells with $\mathrm{X}$-like and $\mathrm{Y}$-like properties in the lateral geniculate nucleus of old-world primates. J. Physiol. (Lond.) 258: 433-453.

Enroth-Cugell, C., and J. G. Robson (1966) The contrast sensitivity of retinal ganglion cells of the cat. J. Physiol. (Lond.) 187: 517-552.

Hicks, T. P., B. B. Lee, and T. R. Vidyasagar (1983) The responses of cells in macaque lateral geniculate nucleus to sinusoidal gratings. J. Physiol. (Lond.) 337: 183-200.

Hochstein, S., and R. M. Shapley (1976) Linear and non-linear spatial subunits in Y cat retinal ganglion cells. J. Physiol. (Lond.) 262: 265284.

Kaplan, E., and R. M. Shapley (1982) X and Y cells in the lateral geniculate nucleus of the macaque monkey. J. Physiol. (Lond.) 330 : $125-144$.

Lee, B. B., V. Virsu, and A. Elepfandt (1983) Cell responses in dorsal layers of macaque lateral geniculate nucleus as a function of intensity and wavelength. J. Neurophysiol. 50: 849-863.

Lee, B. B., P. R. Martin, and A. Valberg (1987a) The physiological basis of heterochromatic flicker photometry. Invest. Opthalmol. Vis. Sci. 28: 240.

Lee, B. B., A. Valberg, D. A. Tigwell, and J. Tryti (1987b) An account of responses of spectrally opponent neurons in macaque lateral geniculate nucleus to successive contrast. Proc. R. Soc. London [Biol.] 230: 293-314.

Lee, B. B., P. R. Martin, and A. Valberg (1988) The physiological basis of heterochromatic flicker photometry demonstrated in the ganglion cells of the macaque retina. J. Physiol. (Lond.) 404: 323-347.

Lee, B. B., P. R. Martiñ, and A. Valberg (1989a) Amplitude and phase of responses of macaque retinal ganglion cells to flickering stimuli. $J$. Physiol. (Lond.) (in press).

Lee, B. B., P. R. Martin, and A. Valberg (1989b) Sensitivity of macaque retinal ganglion cells to chromatic and luminance flicker. J. Physiol. (Lond.) (in press).

Livingstone, M. S., and D. H. Hubel (1987) Psychophysical evidence for separatc channels for the perception of form, color, motion and depth. J. Neurosci. $7: 3416=3468$.

Naka, K.-I., and W. A. H. Rushton (1966) S-potentials from luminosity units in the retina of fish. J. Physiol. (Lond.) 185: $587-599$.

Nunn, B. J., J. L. Schnapf, and D. A. Baylor (1984) Spectral sensitivity of single cones in the retina of Macaca fascicularis. Nature 309:264266.

Perry, V. H., R. Ochler, and A. Cowey (1984) Retinal ganglion cells that project to the dorsal lateral geniculate nucleus in the macaque monkcy. Neuroscience 12; 1110-1123.

Rodieck, R. W. (1965) Quantitative analysis of cat retinal ganglion cell response to visual stimuli.Vision Res. 5: 563-601.

Schiller, P. H., and C. L. Colby (1983) The rcsponses of single cells in the lateral geniculate nucleus of the rhesus monkey to color and luminance contrast. Vision Res. 23: 1631-1641.

Swanson, W. H., T. Ueno, V. C. Smith, and J. Pokorny (1987) Temporal modulation sensitivity and pulse-detection thresholds for chromatic and luminance peturbations. J. Opt. Soc. Am. A 4: 1992-2005.

Tansley, B. W., A. W. Robertson, and K. E. Maughan (1983) In Colour Vision; Physiology and Psychophysics, J. D. Mollon and L. T. Sharpe, eds., pp. 445-454, Academic, London.

Valberg, A., and B. W. Tansley (1977) Tritanopic purity-difference function to describe the properties of minimally distinct borders. J. Opt. Soc. Am. 67: 1330-1335.

Valberg, A., B. B. Lee, and J. Tryti (1987) Simulation of responses of spectrally opponent neurones in the macaque lateral geniculate nucleus to chromatic and achromatic light stimuli. Vision Res. 27: 867882.

van Norren, D., and P. Padmos (1974) Cone dark adaptation; influence of halothane anesthesia. Invest. Opthalmol. 14: 212-227.

Wagner, G., and R. M. Boynton (1972) Comparison of four methods of heterochromatic photometry. J. Opt. Soc. Am. 62: 1508-1515.

Wiesel, T. N., and D. H. Hubel (1966) Spatial and chromatic interactions in the lateral geniculate body of the rhesus monkey. J. Neurophysiol. 29: 1115-1156. 